\title{
Redes organizacionais no contexto da governança pública: a experiência dos Tribunais de Contas do Brasil com o grupo de planejamento organizacional
}

Flávia de Araíjo e Silva, Túlio César Pereira Machado Martins e Ivan Beck Ckagnazaroff

\section{Introdução}

Novos paradigmas organizacionais surgiram nas últimas décadas, motivados por fenômenos como a globalização e a crise fiscal do Estado. O movimento do New Public Management é um exemplo de propostas de mudanças na administração pública, suscitando modificações nas instituições em geral. Assim, alguns valores foram incorporados aos valores tradicionais da cultura do serviço público: eficiência, transparência, diversidade e orientação para o usuário.

Para Castells (1999), surgiu uma nova economia, que é informacional, global e em rede. Novas estratégias e abordagens foram desenvolvidas como respostas diante das mudanças percebidas. As organizações passaram a se concentrar mais em suas "core competences", desenvolver sistemas de informação apropriados e estabelecer redes de cooperação com entidades externas. A associação de organizações em rede, com troca de recursos e informações, é uma estratégia no sentido de agregar valor adicional aos seus membros. 
Nesse contexto, a governança pública aparece como um dos temas principais que têm sido discutidos recentemente, considerando as interações interinstitucionais para a busca de melhores resultados da atuação governamental, e enfatizando efetividade das políticas públicas, assim como maior transparência à sociedade das ações empreendidas com os recursos públicos.

No cenário brasileiro, por exemplo, o Programa de Modernização do Sistema de Controle Externo dos Estados, Distrito Federal e Municípios Brasileiros (Promoex) contemplou como um dos objetivos alcançar maior intercâmbio e cooperação entre Tribunais de Contas (TC), tendo em vista que o diagnóstico realizado em 2002 pela Fundação Instituto de Administração (FIA/USP) apontou que havia baixa integração técnica entre os tribunais, o que levava ao desenvolvimento paralelo de soluções para problemas comuns, e incorria em perda de tempo, recursos e conhecimentos. Também foi apontado que não existiam procedimentos e práticas consolidados para os tribunais, gerando diferentes interpretações sobre os atos julgados (Mazzon; Nogueira, 2002).

Com o advento do Promoex, foram criados grupos temáticos compostos por representantes dos tribunais para discutir e alinhar entendimentos de temas diversos, como auditoria, Lei de Responsabilidade Fiscal, planejamento estratégico etc. Esses grupos temáticos podem ser considerados redes de cooperação.

Desse modo, esta pesquisa busca responder à seguinte questão: que benefícios a adoção de uma rede de cooperação entre os Tribunais de Contas trouxe para os membros dessa rede?

Este trabalho tem por objetivo identificar quais os benefícios da atuação integrada entre instituições públicas sob a perspectiva das organizações em redes, tomando por base a recente experiência do grupo de planejamento organizacional (GPL), considerado como uma rede de colaboração dos Tribunais de Contas, criada a partir do Programa de Modernização do Sistema de Controle Externo dos Estados, Distrito Federal e Municípios Brasileiros (Promoex). Como objetivos específicos, propõem-se: a) descrever a forma como o grupo foi concebido; b) identificar quais foram os méritos alcançados; c) levantar quais foram as dificuldades na interação entre os atores que compõem o GPL.

Adotou-se a metodologia baseada, principalmente, em pesquisa bibliográfica e documental, além de entrevistas com membros do referido grupo.

As pesquisas sobre redes no setor público não são tão desenvolvidas quanto no setor privado, conforme apontam Isett e Provan (2005). Dadas as diferenças existentes entre os setores, faz-se necessário pesquisar de forma mais aprofundada como se dá a interação por meio de redes no setor público.

A atuação das organizações em redes é um tema inovador para o serviço público e deve ser mais explorado, principalmente no que tange aos resultados alcançados pelos integrantes da rede. A ideia de cooperação precisa ser disseminada na administração pública. Nesse sentido, este trabalho pretende contribuir para os estudos no campo das redes organizacionais públicas, por meio de uma reflexão sobre os benefícios proporcionados pelas mesmas aos atores que delas fazem parte.

A fim de atender aos objetivos propostos, este artigo está dividido, para além desta introdução, em cinco seções. A primeira busca discorrer sobre a governança 
pública, identificando os pressupostos dessa abordagem. A segunda apresenta as características das organizações em rede e, em seguida, faz-se a descrição da rede dos Tribunais de Contas. Por fim, são apresentadas as considerações finais.

\section{Governança no setor público}

O advento da Administração Pública Gerencial (APG) ou New Public Management (NPM), a partir dos anos 1980, trouxe uma nova abordagem para a gestão pública ao implementar ferramentas gerenciais até então utilizadas apenas na esfera privada, enfatizando a eficiência e o resultado (HoOd, 1995; PACHECO, 2010; SECCHI, 2009). A APG pode ser entendida como um modelo pós-burocrático e está inserida nos quadros de reformas da administração pública (SECCHI, 2009). A nova gestão pública gerou forte mudança na cultura das organizações, invertendo a antiga orientação de inputs (entradas) para outputs (resultados).

No contexto de mudanças surgidas na gestão pública e ora mencionadas, destaca-se a temática da governança, um modelo de gestão que enfatiza a transparência e accountability. Tal tema, desenvolvido inicialmente nas empresas privadas (governança corporativa) como forma de disciplinar as relações com os acionistas, tem sido disseminado para a esfera pública, como destaca Fontes Filho (2003), mas com um olhar para a sociedade.

A difusão desses modelos tem contribuído para ampliar a discussão da governança para as demais organizações, as não mercantilistas, tais como organizações sem fins lucrativos, organizações sociais e o terceiro setor, (...) e mesmo organizações públicas que estão sujeitas a padrões de aceitação sociais tão importantes à sua sobrevivência quanto o próprio lucro. (FONTES FILHO, 2003, p. 5)

Fontes Filho (2003) afirma que a governança pública está associada a uma mudança na gestão política. Ela pode ser entendida como um novo modelo que apropria dimensões como negociação, comunicação e confiança. O propósito da

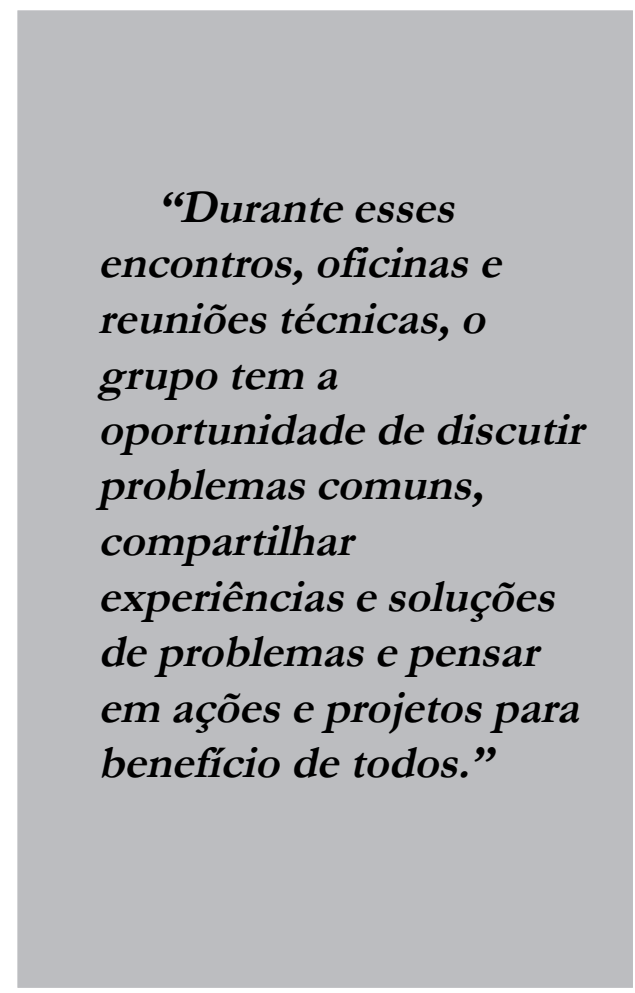

governança, para Kooiman e Van Vliet (1993), não é apenas lidar com problemas, mas também com as oportunidades das sociedades modernas.

Kissler e Heidemann (2006) afirmam não existir um conceito único de governança pública, mas, sim, uma série de considerações acerca de uma nova estrutura das relações entre Estado, iniciativa privada e 
atores da sociedade civil (coletivos e individuais). A governança na administração pública pode ser entendida como um modelo horizontal de relações entre atores das esferas pública e privada no processo de elaboração de políticas públicas (SECCHI, 2009; Kooiman e Van Vliet, 1993).

Para Kissler e Heidemann (2006), a governança pressupõe definição de regras e institucionalização que sejam nem tão fortes, impedindo a capacidade de inovação, e nem tão fracas, com objetivos estratégicos mal formulados, o que poderia comprometer a comunicação entre os membros, além de não favorecer o investimento de pessoas em papéis-chave para a condução dos objetivos. O risco da aliança se perder quando essas pessoas se desvinculam da rede é grande; portanto, Kissler e Heidemann (2006) defendem que:

(...) sem regras de jogo, o sucesso da governança pública se torna antes "obra do acaso" de pessoas engajadas, mas sem papéis vinculantes. As regras do jogo devem ser negociadas entre os atores; e, quando modeladas em conjunto, elas também podem fortalecer o autocomprometimento. (KISSLER e Heidemann, 2006, p. 497)

A governança, no contexto empresarial, está ligada a um conjunto de princípios para aumentar a efetividade de controle pelos stakeholders sobre as instituições com que se relacionam, e também é vista como forma de dirimir os conflitos de agência entre agente e principal. Ao considerar-se a administração pública, Fontes Filho (2003) destaca a necessidade de desenvolver os sistemas de controle interno e externo como forma de monitorar a atuação dos gestores públicos no interesse da sociedade ou grupos de beneficiários.
Kissler e Heidemann (2006) também destacam a ideia de transição de um Estado convencional para um novo modelo de Estado que: (i) serve de garantia à produção do bem público, e; (ii) aciona e coordena outros atores a produzir com ele o bem público. Sob esse aspecto, Kissler e Heidemann (2006, p. 486) ainda comentam que "é decisiva a transição do Estado gestor (hierárquico), com ingerência na sociedade, para o Estado cooperativo, que atua em conjunto com a sociedade e as organizações empresariais, por meio de parcerias estratégicas".

Castells (2001) propõe a definição de Estado-rede, que redefine o Estado-Nação, como aquele que compartilha autoridade (capacidade institucional de impor decisões) com um rol de instituições:

o Estado-Nação se articula cotidianamente na tomada de decisões com instituições supranacionais de distintos tipos e em distintos âmbitos (...), também funcionam em rede nessa mesma rede, instituições regionais e locais. E, inclusive, cada vez mais, dela participam organizações não governamentais (...) que se conectam com essa rede interinstitucional, feita tanto de negociação como de decisão, de compromisso como de autoridade, de informação como de estratégia. (CAstells, 2001, p. 164)

Para Castells (2001), o Estado-rede é uma forma mais apropriada para processar a complexidade de relações entre os diferentes níveis (global, nacional e local), a economia, a sociedade e a política. É a forma política que permite a gestão cotidiana da tensão entre o local e o global. O autor propõe oito princípios de funcionamento administrativo que sintetizam o 
processo de construção do Estado-rede: a gestão administrativa deve situar-se no âmbito mais descentralizado possível; flexibilidade na organização e atuação da administração; coordenação dos elementos que interagem com o Estado, com mecanismos de cooperação, com as administrações locais, regionais, nacionais e supranacionais de todas as instituições presentes na rede operada pelo Estado; participação cidadã; transparência administrativa; modernização tecnológica; profissionalização dos agentes da administração; e retroação na gestão, permitindo às organizações corrigirem seus próprios erros.

Castels (2001) ainda aponta que o Estado-rede é a forma de sobrevivência do Estado na era da informação e da globalização, e que seu instrumento indispensável deve ser uma administração flexível e conectada.

\section{Governança na administração pública por meio de redes}

A rede interorganizacional é um tipo de rede social, com caráter técnico e operacional. Entre suas características, destaca-se pouca hierarquia e grande interatividade entre seus atores. De Sordi et al. (2009) afirmam que a essência de uma rede é o fenômeno da "coopetição", ou seja, cooperação e competição entre empresas. Os elementos fundamentais da rede são os atores e as relações que são estabelecidas entre eles.

Como diria Mintzberg (1998), o governo em rede pode ser entendido como um sistema interligado, uma rede complexa de relações temporárias destinadas à solução de problemas que a todo instante surgem; uma rede ligada por canais informais de comunicação, cujo lema seria conectar, comunicar e colaborar.
Segundo Marini e Martins (2004), rede é uma estrutura de organização capaz de reunir pessoas e instituições em torno de objetivos comuns. Sua base de formação é o compartilhamento da informação. Os autores expõem que o conjunto de redes do governo matricial envolve alinhamento horizontal e vertical. No alinhamento horizontal, as redes podem conter ligações simples, quando programas intrassetoriais são implementados por uma única organização, ou podem ser ligações complexas, em que os programas multissetoriais são implementados por múltiplas organizações, incluindo entidades não governamentais e entes de outras esferas do governo.

Castells (2001) menciona que uma rede não tem centro mas, sim, nós de diferentes dimensões e com relações internodais diferenciadas. Cada nó é necessário para a existência da rede. O autor também afirma que as tecnologias da informação e comunicação é que podem proporcionar a articulação cotidiana de uma rede de instituições complexas, pois, de outra forma, a interatividade dos participantes estaria prejudicada. $\mathrm{O}$ autor acrescenta que "o funcionamento em rede, assegurando descentralização e coordenação na mesma organização complexa, é um privilégio da era da informação" (CASTElls, 2001, p. 164). Castells ainda pondera que o grau de eficiência das administrações estatais dependerá de sua capacidade de processar informações e assegurar o processo de compartilhamento de decisão, o que demandará capacidade tecnológica, recursos humanos adequados e uma estrutura administrativa flexível.

Quando se discute redes, Ahmadjiane (2008) destaca também a criação e compartilhamento do conhecimento entre as organizações que se relacionam, seja esse 
relacionamento próximo ou distante, por meio de vínculos fracos, mas de grande alcance.

Kickert e Koppenjan (1999) comentam que uma análise mais aprofundada acerca da gestão de redes é necessária para se verificar como as redes podem ser utilizadas para desenvolver políticas que busquem solucionar os problemas mais complexos. As organizações entendem que a cooperação é a melhor maneira de atingir objetivos comuns (KLINJ, 1999).

Kissler e Heidemann (2006) apontam que o desenvolvimento da confiança entre os membros de uma rede é um pressuposto para um estado de cooperação. Os autores também explicam que a estrutura de uma rede de atores é composta por fios e nós, sendo os fios as expectativas, objetivos e demandas acerca da atuação dos atores e os nós seriam os próprios atores e sua atuação conjunta. Também expõem que a função de uma rede é reunir atores com interesses diferenciados, ou até conflitantes, para trabalharem em conjunto, buscando agir de acordo com interesses do grupo, e não particulares. Os membros da rede devem negociar os interesses, ajustandose uns aos outros.

Mas o que leva as instituições a se organizarem em rede, tendo em vista essa limitação dos interesses particulares? Para Kissler e Heidemann (2006), a resposta a essa questão é que as redes protegem os atores, ou seja,

Isso quer dizer que elas possibilitam aos atores a resolução de problemas que representariam uma carga excessiva para um ator isolado, único. Em outras palavras: quem trabalha sozinho sucumbe. As redes evitam a queda; possibilitam a solução dos problemas, acima de tudo, pela ação conjunta. Sua estabilidade resulta, assim, da pressão por cooperação e do bom êxito da cooperação. (KISSLER E Heidemann, 2006, p. 495)

Kissler e Heidemann (2006) ressaltam ainda que a governança pública não pode ser imposta: é um processo de troca que oscila entre o topo e a base em toda a organização. Portanto, a nova cultura de governança deve estar impregnada em todas as organizações participantes da estrutura de governança. "Desse modo, os parceiros, liderando uma coalizão em rede ou uma aliança, irão construir efetivamente as bases para o desenvolvimento de uma confiança mútua." (Kissler e HeidemanN, 2006, p. 496).

Os estudos preliminares sobre redes de políticas públicas, por volta dos anos 1960, focavam na importância das relações de cooperação entre organizações, na forma como elas trabalhavam e no impacto dessas relações na estrutura e comportamento organizacional. Acredita-se que grupos interdependentes de duas organizações, colaborando e cooperando uma com a outra, são mais efetivos para prover serviços mais complexos à comunidade do que se atuassem de forma isolada. A lógica por trás disso foi construída nos conceitos da Teoria dos Jogos, que aponta que a cooperação tende a produzir resultados mais favoráveis para ambas as partes do que se as mesmas competissem (Provan E Milward, 2001).

Recentemente, o foco de estudo foi ampliado, buscando verificar a efetividade das atividades da rede e considerando as várias interações entre os atores. É necessário verificar se as redes no setor público realmente funcionam. Entretanto, a dificuldade de avaliar a efetividade de uma rede é ainda maior do que a de avaliar uma 
organização isolada. A avaliação da efetividade deve ser feita pela ótica dos stakeholders. Entretanto, existem diversos stakeholders com visões diferenciadas de como o sucesso da rede deve ser mensurado (Provan e Milward, 2001).

Além dos aspectos ora discorridos sobre as redes de políticas públicas, cabe destacar que as redes de cooperação, de uma forma geral, apresentam alguns benefícios que surgem por meio do relacionamento cooperativo entre os diversos atores que compõem a rede, conforme elencado por Gameiro (2013):

a) melhor aproveitamento dos recursos;

b) partilha de riscos;

c) fortalecimento no poder de negociação (tanto em atividades de compras quanto em atividades de venda), entre outros.

\section{Aspectos metodológicos}

Em termos gerais, a pesquisa possui um caráter descritivo, uma vez que pretende descrever os fatos e fenômenos de uma dada realidade para uma melhor compreensão de como esse processo se desenvolve (TriviÑos, 2007).

Trata-se de uma pesquisa qualitativa, pois apresenta as seguintes características: foco nas percepções e nas experiências dos participantes; concentração no processo que está sob análise; dados são interpretados em relação aos detalhes de um caso e não às suas generalizações (CRESWELL, 2007).

Para atender ao objetivo proposto no presente trabalho - qual seja: identificar quais os benefícios da atuação integrada entre instituições públicas sob a perspectiva das organizações em redes, tomando por base a recente experiência do grupo de planejamento organizacional -, foram utilizadas duas técnicas de pesquisa: documental e entrevista (Martins e Té́filo, 2009).
O grupo de planejamento organizacional (GPL/Promoex) é formado por membros das áreas de planejamento dos Tribunais de Contas dos Estados, Distrito Federal e Municípios do Brasil, assim como por membros de outras instituições públicas, conforme descrição a ser apresentada adiante.

Inicialmente foi feito levantamento de dados por meio de pesquisa documental dos relatórios de atividades, atas de

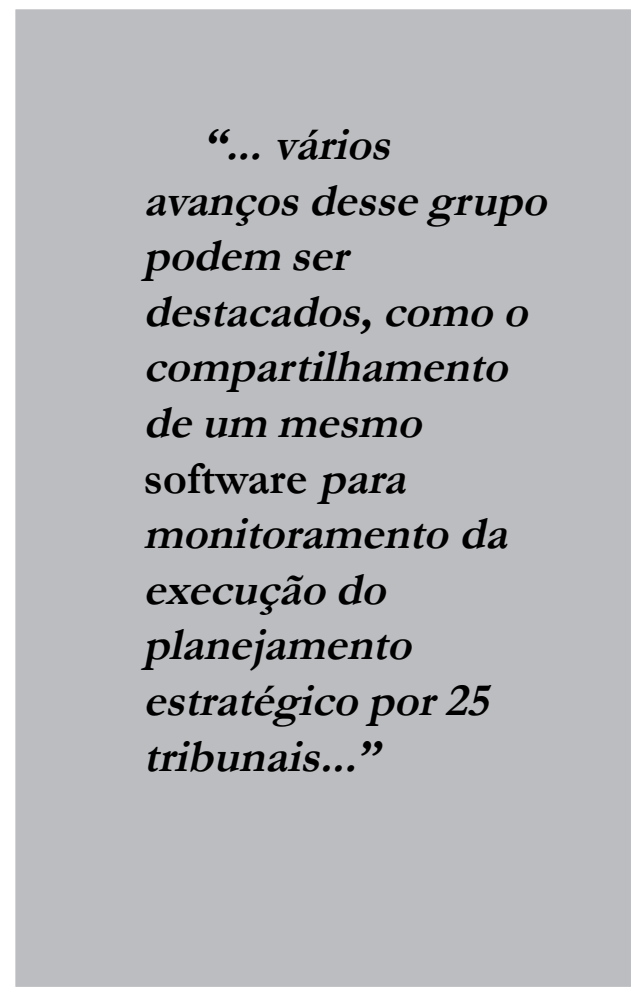

reuniões e encontros técnicos do grupo de planejamento organizacional, disponíveis no Portal dos Tribunais de Contas.

A pesquisa documental também foi realizada por meio de consulta ao Relatório de Progresso Promoex do primeiro semestre de 2012, como forma de identificar dados que pudessem ser utilizados na triangulação com outras fontes de dados 
(entrevistas). Tal relatório encontra-se disponível no site do Ministério do Planejamento, Orçamento e Gestão.

Em seguida, foram realizadas entrevistas não estruturadas cujas características são a liberdade de desenvolvimento das situações nas direções consideradas mais adequadas pelo entrevistador, de forma a explorar amplamente uma questão (Lakatos e Marconi, 2010). As entrevistas tinham a intenção de levantar as percepções dos membros do grupo de planejamento acerca dos avanços alcançados, dificuldades encontradas e ameaças à continuidade dos trabalhos do grupo temático.

Foram entrevistados seis membros do GPL, escolhidos aleatoriamente entre os doze membros do grupo, sendo todos servidores de carreira técnica, que atuam nas unidades de planejamento dos respectivos tribunais. Foram preservadas as identidades dos entrevistados.

Para Lakatos e Marconi (2010), a entrevista é um importante instrumento de investigação social e apresenta como vantagens: oportunidade de obter dados que não se encontram em fontes documentais e que sejam relevantes e significativos; possibilidade de conseguir informações mais precisas, entre outras. Entretanto, algumas limitações desse tipo de pesquisa de campo, apresentadas pelas autoras, são a dificuldade de comunicação entre as partes, retenção de dados importantes devido ao receio de que a identidade do entrevistado seja revelada, além de tomar muito tempo e ser de difícil realização. Levando em conta as vantagens e limitações desse e de outros métodos de pesquisa, considerou-se que a entrevista seria a forma mais adequada para atender aos objetivos propostos neste trabalho.

O roteiro da entrevista foi elaborado segundo a linha da análise SWOT, com identificação dos pontos fortes e fracos do grupo, assim como de oportunidades (desafios) e ameaças. As entrevistas ocorreram durante o mês de dezembro de 2011, direcionadas pelas questões listadas no Quadro 1.

\section{A rede dos Tribunais de Contas}

A proposta do presente trabalho é apresentar um estudo sobre o grupo de planejamento organizacional, sob a perspectiva de organizações em rede de cooperação entre organizações públicas, apontando os benefícios da rede a partir da percepção dos cooperados. Os componentes da rede são servidores dos Tribunais de Contas, entidades que atuam no mesmo ramo (controle externo), mas que não mantêm vínculo entre si. Trata-se de uma rede formada principalmente por instituições com jurisdição estadual/municipal, que conta também com membros de organizações da esfera federal.

Os Tribunais de Contas no Brasil são os órgãos responsáveis pelo controle externo, tendo entre suas competências constitucionais a de apreciar as contas prestadas pelos chefes do Poder Executivo e julgar as contas dos administradores e demais responsáveis por dinheiro, bens e valores públicos da administração direta e indireta (BRASIL, 2012). São órgãos da administração direta e que possuem autonomia administrativa. Entre as principais características, tem-se o caráter colegiado das decisões e o poder coercitivo de impor sanções.

Existem 33 Tribunais de Contas no Brasil: 26 referentes aos Estados da Federação, um do Distrito Federal e seis Tribunais de Municípios (nem todos os Estados optaram por criar um tribunal específico para o município-capital). Cada instituição atua de forma autônoma, não 


\section{Quadro 1: Perguntas para entrevista e objetivos das questões}

\begin{tabular}{|c|c|}
\hline Pergunta & Objetivo \\
\hline $\begin{array}{l}\text { Quais os pontos fortes e fracos do grupo } \\
\text { de planejamento organizacional (GPL)? }\end{array}$ & $\begin{array}{l}\text { Identificar qual a opinião dos integrantes } \\
\text { do grupo acerca dos pontos fortes e fracos } \\
\text { deste, a fim de levantar características do } \\
\text { grupo estudado. }\end{array}$ \\
\hline $\begin{array}{l}\text { Quais foram os avanços alcançados após } \\
\text { criação do GPL? }\end{array}$ & $\begin{array}{l}\text { Identificar quais foram os resultados } \\
\text { advindos da atuação do grupo que não ha- } \\
\text { viam sido atingidos antes da criação do } \\
\text { mesmo. }\end{array}$ \\
\hline Quais foram os maiores méritos do GPL? & $\begin{array}{l}\text { Levantar, entre os resultados alcançados } \\
\text { pelo GPL, aqueles que foram mais impor- } \\
\text { tantes, ou seja, que tiveram maior impacto. }\end{array}$ \\
\hline $\begin{array}{l}\text { Quais foram as maiores dificuldades encon- } \\
\text { tradas pelo GPL desde sua concepção? Você } \\
\text { considera que as dificuldades foram } \\
\text { superadas? }\end{array}$ & $\begin{array}{l}\text { Identificar quais foram as barreiras que o } \\
\text { grupo superou e quais as dificuldades que } \\
\text { ainda persistem para as ações integradas. }\end{array}$ \\
\hline $\begin{array}{l}\text { Existem ameaças/entraves à continuidade } \\
\text { do grupo? Quais são essas ameaças? }\end{array}$ & $\begin{array}{l}\text { Identificar se existem aspectos que podem } \\
\text { vir a interromper as atividades do grupo. }\end{array}$ \\
\hline $\begin{array}{l}\text { Quais os principais desafios para o GPL que } \\
\text { estão por vir? }\end{array}$ & $\begin{array}{l}\text { Levantar a percepção dos integrantes acer- } \\
\text { ca de questões complexas e desafiadoras } \\
\text { para o grupo. }\end{array}$ \\
\hline $\begin{array}{l}\text { Você considera que o GPL contribuiu para } \\
\text { as ações de modernização dos Tribunais de } \\
\text { Contas? Em que medida? }\end{array}$ & $\begin{array}{l}\text { Identificar qual a opinião dos integrantes } \\
\text { acerca dos benefícios para os Tribunais de } \\
\text { Contas por meio de ações de moderniza- } \\
\text { ção, a saber: planejamento estratégico, } \\
\text { redesenho de processos etc. }\end{array}$ \\
\hline
\end{tabular}

Fonte: Elaborado pelos autores.

tendo sido criado ainda um órgão central que dite regras para todos os Tribunais de Contas. Será contextualizado, a seguir, o programa do governo federal, Promoex, que proporcionou, entre outras ações de destaque, a criação do grupo de planejamento organizacional (GPL).

\section{O programa Promoex}

Pesquisa realizada em 2002 pela Fundação Instituto de Administração da Universidade de São Paulo, com intuito de elaborar um diagnóstico dos Tribunais de Contas, apontou a existência de um rol de problemas, entre eles: falta de planejamento e controle gerencial; falta de maior integração e homogeneização de procedimentos e decisões; baixo nível de disseminação das melhores práticas entre os tribunais; prevalecimento do esforço individual em detrimento do coletivo, levando ao desenvolvimento paralelo de soluções para problemas comuns, com perda de tempo, recursos e conhecimento; burocratização das atividades; lentidão das respostas (MAZzoN E Nogueira, 2002). 
Diante desse cenário, foi criado o programa Promoex, com início no ano de 2006 e previsão inicial de término para 2009, mas estendido para junho de 2012, objetivando "a modernização do conjunto de Tribunais de Contas que atuam nos Estados, Distrito Federal e Municípios, principalmente por meio da capacitação de pessoal, introdução de novos procedimentos e sistemas organizacionais e investimentos em informática" (Portal dos Tribunais DE Contas do Brasil, 2011). Inicialmente composto por 32 dos 33 Tribunais de Contas do Brasil, o Promoex, em 2011, era composto por 28 deles.

Abrucio (2007) discorre sobre os programas de modernização comandados pelo Governo Federal, como o Programa Nacional de Apoio à Modernização da Gestão e do Planejamento dos Estados e do Distrito Federal (Pnage) e o Promoex:

Depois de duas décadas de reformas nas quais a redução do aparato e dos gastos estatais constituiu o fio condutor do processo, o Pnage e o Promoex priorizaram a reconstrução da administração pública em suas variáveis vinculadas ao planejamento, aos recursos humanos, à sua interconexão com as políticas públicas e ao atendimento dos cidadãos. (ABrucio, 2007, p. 78)

Abrucio (2007) também comenta as qualidades do programa, como a realização de um diagnóstico sobre a situação dos Tribunais de Contas, em vez da proposição de modelos fechados aos Estados. O autor também comenta que

o maior avanço do Pnage/Promoex foi construir tais programas por meio de ampla participação e discussão com os Estados e Tribunais de Contas. Esse modelo intergovernamental e interinstitucional é mais participativo e funciona mais em rede do que de forma piramidal. (ABRUCIO, 2007, p. 78)

Segundo Loureiro, Teixeira e Moraes (2009), o programa está inserido no contexto de modernização da administração pública e tem gerado grande impacto nos Tribunais de Contas, pois, além de atuar na modernização tecnológica, tem alterado as relações de poder internas entre conselho deliberativo e corpo técnico. Os técnicos têm participado mais dos processos decisórios, ao conduzirem o desenvolvimento do programa dentro dos tribunais e ao manterem contato direto com o Ministério do Planejamento e organismos internacionais. "Isso lhes traz visibilidade externa e lhes permite desenvolver ações conjuntas e articuladas em nível nacional e mesmo internacional" (Loureiro; Teixeira; Moraes, 2009, p. 754).

Um dos membros do GPL comentou, durante a entrevista, que "o Promoex foi um marco para todos os Tribunais de Contas", na medida em que o cenário, que se pode verificar nessas cortes de contas após o programa, é bem diferente daquele encontrado antes do início do programa, uma vez que essas se tornaram mais modernas, em termos dos procedimentos e modelos de gestão.

Um dos objetivos do Promoex é o fortalecimento e integração dos Tribunais de Contas. Até o início do programa, cada tribunal atuava de forma isolada e com pouco compartilhamento de experiências e entendimentos técnicos. Uma das soluções para aumentar a integração foi a criação de grupos temáticos formados por representantes de cada tribunal de contas, com intuito de compartilhar informações, 
ferramentas de gestão e discutir assuntos técnicos para harmonizar o entendimento dessas instituições, principalmente no que tange à aplicação da Lei de Responsabilidade Fiscal.

Existe ainda a Associação dos Membros dos Tribunais de Contas do Brasil (Atricon), que também objetiva o entrosamento e a coordenação das atividades das cortes de contas (PORTAL Dos TRIBUnAis DE CONTAS DO BRAsil, 2011). Porém, os encontros dessa associação são direcionados aos conselheiros dos tribunais, ou seja, são encontros que apresentam cunho político. Já o escopo dos encontros dos grupos temáticos, em que se reúnem servidores/gestores das diversas áreas, é mais técnico, com intuito de estudar/aprimorar os procedimentos e práticas.

Os grupos temáticos nacionais focam nas seguintes áreas: grupo de responsabilidade fiscal; grupo de planejamento organizacional; educação corporativa; comunicação institucional; tecnologia da informação; gestão de pessoas; auditoria operacional; atos de pessoal; procedimentos contábeis; padronização de relatórios; contas de governo; processo eletrônico e sistematização de informações contábeis e fiscais.

O objeto de estudo desse trabalho será o grupo de planejamento organizacional, detalhado a seguir.

\section{Histórico do grupo de planejamento organizacional}

O grupo de planejamento organizacional (GPL) foi criado no final de 2008 com a finalidade de apoiar a efetiva implantação do planejamento estratégico e o aprimoramento gerencial, bem como contribuir para a integração e o compartilhamento de conhecimentos e experiências entre os Tribunais de Contas (com o passar dos anos, os objetivos foram expandidos, como atuar no apoio ao redesenho de processos de trabalho e construção de indicadores de desempenho). Inicialmente, esteve sob coordenação de um servidor do Tribunal de Contas do Estado de Tocantins por um período de um ano. A partir do ano de 2009, passou a ser coordenado por uma servidora do Tribunal de Contas do Estado de Minas Gerais. O grupo é composto por 12 membros: dois do Tribunal de Contas da União (TCU), um

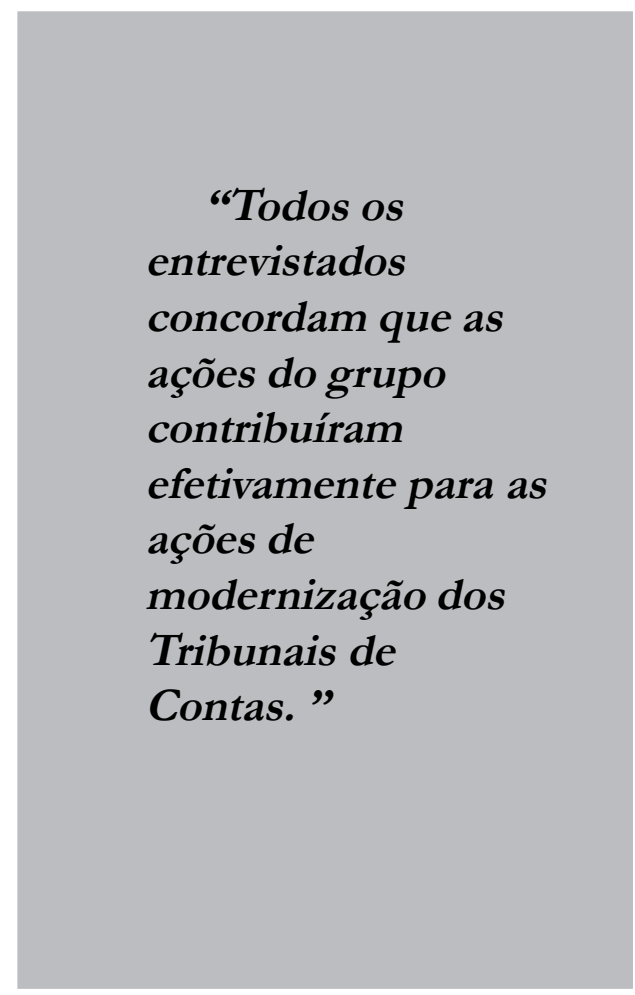

da Atricon, um do Instituto Rui Barbosa (IRB), e por oito membros dos Tribunais de Contas Estaduais. Para fortalecer as ações do GPL, foi criado um grupo de e-mails chamado "GPLAN", que é integrado por cerca de 90 servidores das áreas de planejamento de todos os Tribunais de Contas, que também se encontram periodicamente nos eventos do 
GPL. Desse modo, os atores da rede são técnicos dos Tribunais de Contas ou de instituições de apoio aos tribunais (Atricom e IRB), além dos dois membros do TCU.

Antes mesmo da criação do GPL, representantes das áreas de planejamento já haviam-se reunido em dois momentos, no ano de 2008, no Encontro de Planejamento no Tribunal de Contas do Estado de Tocantins e na I Oficina de Capacitação do TCU, cujo tema foi plano estratégico e mapeamento de processos. Após sua concepção, o grupo se reuniu em diversos momentos, conforme descrição no Quadro 2.

Durante esses encontros, oficinas e reuniões técnicas, o grupo tem a oportunidade de discutir problemas comuns, compartilhar experiências e soluções de problemas e pensar em ações e projetos para benefício de todos. A possibilidade dos integrantes se conhecerem e interagirem pessoalmente reforça o vínculo entre os mesmos. Cabe ressaltar que, considerando que a extensão geográfica é um fator dificultador para que os encontros possam ocorrer com maior frequência, tendo em vista, também, os recursos financeiros que são necessários para o deslocamento dos participantes, o grande quórum desses eventos pode refletir a adesão e compro- metimento dos Tribunais de Contas com o grupo. Na maioria dos eventos estiveram presentes representantes da quase totalidade dos Tribunais de Contas. Ainda com relação a esse tema, Baker, Kan e Teo (2011) também mencionaram a questão geográfica como uma barreira à colaboração entre os membros de uma rede australiana estudada, devido à impossibilidade de acontecerem contatos face a face com frequência.

Além dessa interação durante os encontros presenciais, o grupo mantém contato por e-mails, por telefonemas e visitas técnicas. Frequentemente, o grupo troca documentos (minutas de regulamentações e formulários), contatos de empresas de consultoria e treinamento, escopo de projetos, entre outros. É utilizado, para consulta de documentos, o Portal dos Tribunais de Contas do Brasil (Controle Público), que dispõe de um ambiente de colaboração em que podem ser encontradas, em ambiente restrito aos membros, atas de reuniões, apresentações dos encontros, guias e manuais de consulta.

No início do ano de 2009, apenas 14 tribunais participantes do Promoex haviam elaborado plano estratégico. Uma das metas do Promoex era que $100 \%$ dos participantes

\section{Quadro 2: Eventos do grupo de planejamento organizacional}

\begin{tabular}{|l|l|}
\hline Data & Evento \\
\hline 2009 & $\begin{array}{l}\text { Seminário de Soluções Compartilhadas e I Reunião Técnica, em } \\
\text { Curitiba/PR }\end{array}$ \\
\hline Abril/2010 & $\begin{array}{l}\text { I Encontro de Planejamento Estratégico, em Natal/RN, contando } \\
\text { com a participação dos conselheiros e técnicos }\end{array}$ \\
\hline Agosto/2010 & II Oficina de Capacitação, no TCU \\
\hline Maio/2011 & II Reunião Técnica, no Distrito Federal \\
\hline Junho/2011 & Reunião Técnica, no Distrito Federal \\
\hline Setembro/2011 & II Encontro de Planejamento Estratégico, em Porto Alegre/RS \\
\hline
\end{tabular}

Fonte: Relatório de atividades do grupo de planejamento/Promoex. 
tivessem o planejamento estratégico criado e implementado até o final do programa. Essa meta foi alcançada no ano de 2012, em que dois tribunais restantes estavam implantando o primeiro ciclo de planejamento estratégico. Cabe ressaltar que, nesse processo de formulação do plano estratégico, vários tribunais trocaram informação entre si, uma vez que alguns deles estão à frente do processo e outros estavam começando. Em pesquisa realizada nos Tribunais de Contas, Silva e Gonçalves (2011) pontuaram que oito dos 10 tribunais respondentes utilizaram como referência para elaboração do seu plano estratégico o plano de outros tribunais, sendo o TCU citado por três dos respondentes.

O grupo de planejamento organizacional formou cinco grupos menores para discutir temas específicos como: (i) indicadores, (ii) redesenho de processos, (iii) monitoramento do plano estratégico por meio de software, (iv) documentação e (v) eventos. Cada subgrupo interage por meio de troca de e-mails e conversas por telefone, e apresentam os resultados discutidos/pesquisas realizadas para todo o grupo em encontros presenciais.

\section{Pontos fortes, avanços alcançados e méritos do GPL segundo os entrevis- tados}

Em quase três anos de existência, vários avanços desse grupo podem ser destacados, como o compartilhamento de um mesmo software (adquirido e disponibilizado pelo IRB) para monitoramento da execução do planejamento estratégico por 25 tribunais, durante o ano de $2011^{1}$. Essa ação está em linha com o alcance de outra meta do Promoex, qual seja: 30\% dos Tribunais de Contas utilizando soluções técnicas compartilhadas. Cabe destacar, também, que o sistema informatizado foi licitado com base em especificações técnicas definidas de modo a atender às necessidades dos tribunais. Criou-se um grupo eletrônico de discussão para compartilhar experiências e dúvidas comuns nessa fase de implementação do software. Frequentemente, um tribunal entra em contato com outro, por telefone ou até mesmo em visita técnica, para tirar dúvidas quanto à utilização do sistema.

A gestão em rede permite contratações em maior volume, gerando economia de escala. Se cada tribunal fosse adquirir, de forma independente, um software de planejamento estratégico, o montante total desembolsado seria muito superior à cifra paga pelo IRB para aquisição da solução compartilhada. Cada tribunal adquirente paga apenas um valor mensal referente a suporte e manutenção. Isso também demonstra a força da atuação em conjunto, gerando economicidade para a máquina pública, além do compartilhamento de informações, também referente à metodologia, durante a implantação dos softwares.

Outra ação que possibilitou economia de recursos foi o repasse da metodologia de elaboração e desdobramento do planejamento estratégico do TCU diretamente a vários tribunais por meio de oficinas de trabalho. Nesses encontros, os tribunais tiveram de arcar apenas com custos de diárias e passagens dos servidores do TCU. Se tivessem que contratar consultoria para tanto, além de incorrer em custos elevados, talvez não tivessem a experiência prática daqueles que lidam com as especificidades de um órgão público de controle externo.

Outro tema discutido pelo grupo é o redesenho de processos, que também é uma das metas do Promoex: 50\% dos processos de trabalho finalísticos do tribunal redesenhados e manualizados até o final do programa. Praticamente todos os 
tribunais participantes do Promoex já iniciaram procedimentos ou realizaram redesenho de algum processo, buscando, assim, reduzir desperdícios de recursos (tempo, dinheiro, mão de obra).

Um dos entrevistados ressaltou que os avanços alcançados pelo grupo também podem ser creditados a uma coordenação efetiva das atividades: "temos a sorte de ter uma coordenadora atuante" (Entrevistado 1). Esse entrevistado também destacou outro ponto forte: o grupo, atualmente, encontra-se muito unido e os participantes sempre buscam ajudar uns aos outros.

Os grupos temáticos também perceberam a necessidade da atuação conjunta entre eles, por exemplo, o GPL atuando em conjunto com os demais grupos quando os assuntos se relacionarem. Por isso, a reunião do grupo de educação corporativa, realizada em 2011, contou com a participação da coordenadora do GPL para, juntos, planejar ações para o ano de 2012, com intuito de alinhar os objetivos dos grupos.

Entrevistas realizadas com membros do GPL demonstraram que um dos grandes méritos do grupo foi a aproximação dos tribunais, gerando a possibilidade de conhecer outras experiências e de enxergar novas formas de aplicação prática em cada tribunal que participa do grupo por meio de um/vários representantes. Um dos entrevistados chegou a destacar que esse foi o maior mérito, maior ainda que os recursos financeiros advindos do programa.

Antes da criação do grupo, essa comunicação entre servidores das áreas de planejamento dos tribunais não era comum. Conforme explicou um dos entrevistados, metodologias podem ser implementadas por meio de contratação de consultorias; porém, o compartilhamento de informações entre membros do GPL permitiu que os tribunais verificassem a aplicabilidade dessas metodologias, considerando as peculiaridades desses órgãos que atuam no mesmo segmento. Os membros do GPL puderam verificar como as práticas estavam sendo desenvolvidas em contextos distintos, e adaptar a aplicação para cada tribunal, considerando situações semelhantes. A disseminação do conhecimento entre os servidores dos tribunais foi enorme, segundo os entrevistados.

Outra grande conquista foi a criação da base documental que, mesmo estando ainda incipiente, possibilita aos membros dos grupos temáticos (não só do GPL) o acesso a uma gama de informações, como modelos, práticas e metodologia de gerenciamento aplicado aos tribunais. Trata-se de um rico acervo de conhecimento disponível para os tribunais.

Todos os entrevistados concordam que as ações do grupo contribuíram efetivamente para as ações de modernização dos Tribunais de Contas. Além do planejamento estratégico implantado em todos os tribunais que não haviam adotado a prática de gestão até então, e dos avanços acerca da definição e mensuração de indicadores de desempenho, o grupo discutiu também o redesenho de processos.

\section{Dificuldades encontradas, pontos fracos e desafios para o grupo segundo os entrevistados}

Esses méritos do grupo foram conquistados mesmo em meio a várias dificuldades encontradas. Informações obtidas nas entrevistas indicam que alguns dos entraves para uma melhor interação do grupo foram devidos a barreiras na comunicação, características de estrutura hierárquica rígida das instituições públicas. Essas dificuldades se destacaram bastante no início das atividades do grupo: as solicitações e/ou pesquisas sobre procedimentos 
e dados dos tribunais não eram facilmente conseguidas; geralmente, tinha de ser elaborado um pedido formal para encaminhamento às chefias superiores, mesmo para as solicitações mais simples. Essas barreiras foram sendo quebradas ao longo do tempo, pois os membros do grupo foram conquistando confiança uns com os outros. Atualmente, a comunicação entre os membros é mais fluida, proporcionando troca de informação rica e ágil. Os entrevistados acreditam que, de forma geral, os membros do grupo já têm a consciência do benefício da cooperação para todos os tribunais.

Quanto à dificuldade de comunicação, foram levantadas possíveis causas. Uma delas pode ser o receio da exposição de fraquezas e debilidades da instituição, que, porventura, pudessem gerar repercussões negativas. Alguns atores podem preferir não se comprometer a prestar informação sobre seu tribunal, já que não há obrigatoriedade, deixando, assim, de ter responsabilidade sobre a informação prestada e possíveis questionamentos.

Outra questão que dificultou a comunicação durante os primeiros passos do grupo foi o desconhecimento, por grande parte dos integrantes, sobre o tema do planejamento estratégico. A cultura de planejamento não era, e talvez ainda não seja, uma realidade em todos os tribunais. Após várias reuniões e oficinas de trabalho para discussão do tema, este passou a ser de conhecimento geral dos tribunais, ou seja, tem-se atualmente um nivelamento conceitual. Segundo a percepção dos entrevistados, o grupo está mais homogêneo e consegue evoluir para discussões mais aprofundadas sobre temas como indicadores de desempenho, desdobramentos do planejamento, entre outros.

Conseguir manter a participação ativa dos integrantes do GPLAN é outra dificul- dade apontada. Alguns membros são mais atuantes; entram em contato frequentemente com os demais e participam das pesquisas. Entretanto, outros não se envolvem tanto. Algumas pessoas que já tiveram participação consistente podem também se desligar do grupo devido à perda de cargo em comissão ou transferência para outra área do tribunal.

Outra questão pontuada por um dos entrevistados é que, em alguns períodos, a participação nas atividades do grupo pode ser reduzida em virtude de um momento específico pelo qual passa a unidade de planejamento de determinado tribunal: a redução brusca do número de servidores lotados na referida unidade é um fator complicador para a conciliação das atividades do órgão com as atividades do grupo, já que essa requer um envolvimento por meio de participação em pesquisas, organização de eventos, discussão de temas, entre outros. Também foi destacada a dificuldade de conciliar as demandas do projeto Promoex (elaboração dos relatórios, acompanhamento de execução, atendimento a auditorias, entre outros) - que é um trabalho complexo e que demanda bastante tempo - com as atividades de monitoramento. Geralmente, as atribuições da Coordenação Técnica do Promoex são dirigidas aos servidores que compõem a unidade de planejamento estratégico.

Um dos entrevistados, em contrapartida, ponderou como dificuldade o fato de a unidade de planejamento não ser a responsável pela Coordenação Técnica do Promoex, ocasionando falta de uniformidade da informação acerca dos eventos/ acontecimentos do Promoex.

Um dos entrevistados também destaca a questão da competitividade entre os tribunais como uma grande dificuldade a ser superada pelo grupo. Um tribunal que adota 
práticas de gestão desenvolvidas einovadoras pode querer divulgar e disseminar seus procedimentos; entretanto, aqueles tribunais que não estão tão desenvolvidos podem não ter interesse em disponibilizar informações. Essa competitividade também gera bloqueio das informações, sendo um entrave à comunicação do grupo.

Outro ponto fraco, citado por alguns dos entrevistados, reside no fato de que os tribunais apresentam grandes diferenças entre si em relação à estrutura organizacional, ao porte (número de jurisdicionados), às normas processuais, entre outros. Esses fatores são dificultadores para a uniformização de práticas e para a discussão e adoção, por exemplo, de indicadores comuns e benchmarks.

As entrevistas também revelaram que um grande desafio para o GPL será a continuidade da integração do grupo, após o encerramento do programa Promoex, que estava previsto para junho de 2012. Na época das entrevistas, já estavam sendo estudadas medidas para minimizar os efeitos do encerramento do programa e, também, contribuir com a continuidade dos grupos temáticos. Um dos entrevistados ponderou que é necessário fazer um trabalho de conscientização da importância da integração entre os representantes dos tribunais junto à alta administração para dar respaldo e continuidade às ações do grupo, principalmente após o fim do programa, momento em que os recursos do projeto, destinados aos encontros técnicos deixariam de existir.

\section{Resultados apurados no Relatório de Progresso do Promoex}

Como forma de verificar se os relatos das entrevistas poderiam ser confirmados pelos relatórios oficiais do programa, foi consultado o Relatório de Progresso
Promoex do $1^{\circ}$ Semestre de 2012. Tal relatório apresenta os avanços do Promoex, considerando as execuções acumuladas até dezembro de 2011 e até junho de 2012. No relatório citado, no Quadro V - Execução física por subcomponentes nacionais e locais -, estão apresentadas as medições das metas até as datas mencionadas. Apresentamos no Quadro 3 as metas referentes ao componente nacional, pois estão mais diretamente relacionadas com o objeto deste estudo.

Verifica-se, então, que $75 \%$ das metas do componente nacional foram atingidas. Em relação à mensuração da meta do subcomponente 1.3, consta uma explicação no Relatório de Progresso:

A mensuração física para verificação do alcance da meta prevista para este subcomponente iniciou-se somente após a realização dos Seminários de Ações Compartilhadas, que ocorreram em agosto e novembro de 2009. O Portal Nacional dos TC disponibiliza uma sugestão de termo de cooperação, visando facilitar, se necessário, as formalizações das ações compartilhadas. Como resultado das ações compartilhadas, verificou-se uma redução no número de contratações de terceiros, especialmente de consultorias, cujo impacto econômico ainda será medido pelo Promoex (BRAsil, 2013, grifo nosso).

Desse modo, está explicitado no relatório que houve uma redução do número de contratações de consultorias pelos tribunais desde o advento do programa, passando, esses, a compartilhar informações entre si, em consonância com o exposto pelos entrevistados em relação aos benefícios proporcionados pelo Promoex. 


\section{Quadro 3: Metas estratégicas Promoex}

\begin{tabular}{|c|c|c|c|}
\hline $\begin{array}{l}\text { Componente/ } \\
\text { Subcomponente }\end{array}$ & Meta & Indicador & $\begin{array}{l}\text { Medição } \\
\text { até } 1^{\circ} \\
\text { semestre } \\
\text { de } 2012\end{array}$ \\
\hline 1 & $\begin{array}{l}33 \text { Tribunais de Contas (TC) } \\
\text { cooperando em rede. }\end{array}$ & $\begin{array}{l}\text { Número de tribunais cooperando } \\
\text { em rede. }\end{array}$ & 33 \\
\hline 1.1 & $\begin{array}{l}17 \text { TC interligados à Rede } \\
\text { Nacional dos TC e integrados } \\
\text { ao portal, coordenados pelo } \\
\text { IRB e Atricon até o final da } \\
\text { execução dessa fase do programa. }\end{array}$ & $\begin{array}{l}\text { Número de TC participantes da } \\
\text { rede e do Portal Nacional dos TC. }\end{array}$ & 16 \\
\hline 1.2 & $\begin{array}{l}14 \text { dos } 28 \text { conceitos e } \\
\text { procedimentos selecionados } \\
\text { pelo Fórum dos TC (referentes } \\
\text { à LRF e a outros gastos } \\
\text { públicos), harmonizados/ } \\
\text { redesenhados e implantados } \\
\text { até o final da execução dessa } \\
\text { fase do programa. }\end{array}$ & $\begin{array}{l}\text { Número de conceitos e } \\
\text { procedimentos selecionados pelo } \\
\text { Fórum dos TC (coordenado pelo } \\
\text { IRB/Atricon), harmonizados/ } \\
\text { redesenhados e implantados. }\end{array}$ & 26 \\
\hline 1.3 & $\begin{array}{l}11 \text { TC com soluções técnicas } \\
\text { compartilhadas até o final da } \\
\text { execução dessa fase do programa. }\end{array}$ & $\begin{array}{l}\text { Número de TC com soluções } \\
\text { técnicas compartilhadas. }\end{array}$ & 20 \\
\hline
\end{tabular}

Fonte: Relatório de Progresso $1^{\circ}$ Semestre de 2012 - Quadro V: Execução física por subcomponentes nacionais e locais.

As soluções compartilhadas refletem uma redução de dispêndios que ainda não foi mensurada pelo programa, mas que já é nítida. De acordo com o Relatório de Progresso: "Considera-se como solução compartilhada, quando há produto comprovado documentalmente, por meio de qualquer instrumento. Computa-se o compartilhamento de solução para todos os partícipes da ação".

Outros pontos destacados no Relatório de Progresso (Brasil, 2013):

a) Todos os 33 tribunais já se encontram cooperando em rede, inclusive os que não participam atualmente do programa, apontando para um grande engajamento no fortalecimento do sistema de controle externo brasileiro.

b) Vinte tribunais estão compartilhando soluções de TI e outras, a exemplo de elaboração e implementação de planejamento estratégico, de sistemas de captura eletrônica de contas, e de processos de análises de contas de governo e de atos de pessoal.

\section{Reflexões a serem consideradas em pesquisas futuras}

Diante do cenário exposto, levantamse algumas questões a serem analisadas com mais profundidade: quais as formas de se manter o vínculo e a atuação efetiva dos integrantes do grupo? Quais as estratégias para não perder pessoas com papéis-chave para a condução dos objetivos do grupo? Qual a disposição das instituições para atuação em rede? Como motivar os líderes dos grupos para que permaneçam exercendo a função? 
Cabe destacar que a função de coordenação dos grupos temáticos do Promoex é um trabalho extra, realizado por servidores de alguns tribunais, e não há remuneração adicional para tanto. Entretanto, para que as ações sejam efetivas, muito esforço é desprendido por esses coordenadores, que trabalham em prol de um objetivo maior, qual seja, a interação e compartilhamento de informações entre os tribunais para desenvolvimento desses. Uma opção a ser considerada, talvez, seja criar instrumentos de motivação para participação nos grupos, como forma também de se reconhecer o mérito dos resultados alcançados por meio dos esforços das ações realizadas, já que se trata de um trabalho que consome bastante tempo e dedicação. O estabelecimento de incentivos (pecuniários ou não) poderia, por exemplo, mitigar os riscos de não continuidade das ações do grupo com a perda de uma liderança ativa. Alguns coordenadores de grupo tiveram de abdicar da função em virtude do acúmulo de trabalho e da incompatibilidade de conduzir as atividades do seu próprio cargo com as da função de coordenação.

Para responder a essas questões, necessário se faz elaborar um instrumento de pesquisa muito bem estruturado, que possa levantar as percepções dos representantes dos tribunais que acompanham as atividades do grupo.

\section{Considerações finais}

O presente trabalho se propôs a descrever a experiência de atuação integrada de colaboradores das áreas de planejamento dos Tribunais de Contas, por meio do grupo de planejamento organizacional/Promoex, respondendo à seguinte questão: que benefícios a adoção de uma rede de cooperação entre os TC trouxe para os membros dessa rede?

Foram realizadas entrevistas com membros do grupo para levantar as percepções acerca dos avanços alcançados, dificuldades encontradas e ameaças à continuidade dos trabalhos do grupo temático.

Um dos benefícios para os membros da rede é a interação que os representantes dos tribunais passaram a ter após os encontros do grupo, ponto de mérito destacado por todos os membros do GPL entrevistados - trata-se de um resultado de difícil mensuração, em termos de avaliação dos resultados do programa Promoex, mas de vital importância para os servidores que fazem parte dessas organizações. Além de troca de informações, compartilhamento de experiências e desenvolvimento em conjunto, a mobilização do grupo proporcionou também economicidade ao erário, como, por exemplo, ao adquirir uma solução informatizada compartilhada, assim como ao receber consultoria de outros tribunais, em vez de efetuar contratação com empresa privada. Tais aspectos vão ao encontro do preconizado pela Teoria das Redes.

Os resultados das entrevistas apontam que a troca de informações entre o grupo proporcionou enriquecimento para as unidades de planejamento e, consequentemente para os tribunais, uma vez que o planejamento estratégico é um tema que tem implicações em toda organização. A vontade de colaborar uns com os outros é uma característica marcante dos membros do grupo estudado.

Verificou-se que os avanços alcançados por essas áreas, promovendo uma atuação conjunta e considerando valores como eficiência e efetividade, dificilmente seriam realizados caso tais instituições continuassem a atuar de forma isolada. 
Grande parte dos membros do grupo avançou para um estágio de desenvolvimento em que esses conseguem enxergar seus tribunais como "iguais", no sentido de que seriam organizações com problemas semelhantes e que buscavam o desenvolvimento das práticas de gestão, para alcançarem melhores resultados. Diante dos depoimentos dos entrevistados acerca dos resultados alcançados pelo grupo, pode-se entender que as ações do GPL foram positivas, proporcionando um avanço para a gestão dos Tribunais de Contas, além de terem atuado diretamente nos problemas diagnosticados pela pesquisa da FIA/USP, quais sejam: falta de planejamento, falta de integração e homogeneização de procedimentos, baixo nível de disseminação das melhores práticas entre os tribunais e prevalecimento do esforço individual em detrimento do coletivo.

Se, por um lado, essa interação entre representantes dos tribunais resulta na exposição das fraquezas da instituição, ao passo que nas discussões do grupo são feitos relatos da situação em que se encontra cada órgão; por outro lado, é uma oportunidade de compartilhar problemas comuns para se pensar em conjunto soluções adequadas. Essa é a ênfase que deve ser dada para a cultura da cooperação entre instituições públicas. Não faz sentido cada órgão atuar como uma ilha isolada, enfrentando problemas comuns a outras instituições, se pode haver troca de experiências entre elas para benefício mútuo.

Todos os resultados alcançados pela atuação do grupo refletem uma atuação da administração pública rumo à excelência na prestação de serviços com qualidade, eficiência e eficácia.

Uma limitação deste trabalho é que as percepções sobre a cooperação entre os tribunais restringiram-se apenas à atuação do grupo de planejamento organizacional. Como existem vários outros grupos temáticos no âmbito do Promoex, fica como sugestão de pesquisa futura a análise dos resultados alcançados por esses outros grupos.

(Artigo recebido em maio de 2013. Versão final em junho de 2013.)

\section{Nota}

${ }^{1}$ Alguns tribunais não aderiram ao convênio que foi assinado com o Instituto Rui Barbosa, muitos deles pelo fato de já possuírem um sistema informatizado. 


\section{Referências bibliográficas}

Abrucio, F. L. Trajetória Recente da Gestão Pública Brasileira. Revista de Administração Pública. Rio de Janeiro: Edição Especial Comemorativa 67-86, 1967-2007.

Ahmadjian, C. L. Criação do conhecimento inter-organizacional: conhecimento e redes. In: Takeuchi, H.; Nonaka, I. Gestão do conhecimento. Porto Alegre: Bookman, 2008.

BAKer, E.; KAN, M.; TeO, S. T. T. Developing a collaborative network organization: leadership challenges at multiple levels. Journal of Organizational Change Management, v. 24, no 5, p. 853-875, out, 2011.

Brasil. Ministério do Planejamento, Orçamento e Gestão. Promoex. Relatório de Progresso Promoex - 1 Semestre de 2012. Disponível em: http://www.planejamento. gov.br/secretaria.asp?cat $=487 \&$ sec $=18$. Acesso em: 18 abr. 2013.

Castells, Manuel. A sociedade em rede. São Paulo: Paz e Terra, 1999.

M. Para o Estado-rede: globalização econômica e instituições políticas na era da informação. IN: Bresser Pereira, L. C., Wilheim, J. e sola, L. (orgs.). Sociedade e Estado em transformação. São Paulo: Editora UNESP, 2001. Capítulo 4, p. 147-172.

Creswell, J. W. Projeto de pesquisa: métodos qualitativo, quantitativo e misto. Tradução de Luciana de Oliveira da Rocha. 2 ed. Porto Alegre: Artmed, 2007.

De Sordi, J. O.; Picchiai, D.; Costa, M. A. M.; Sanches, M. A. Competências críticas ao desenvolvimento de mapas cognitivos de redes interorganizacionais. Revista de Administração Pública. Rio de Janeiro, v. 43, nº 5, p. 1181-1206, set./out. 2009.

Fontes FilHo, J. R. Governança organizacional aplicada ao setor público. In: VIII CONgresso Internacional Del CLAD sobre la Reforma Del estado y de La Administración Publica, 2003, Panamá. p. 28-31.

Gameiro, Paulo Alexandre Dias. As Organizações em Rede. Universidade Lusófona de Humanidades e Tecnologias. Disponível em: < http://bocc.ubi.pt/pag/gameiro-pauloas-organizacoes-em-rede.pdf>. Acesso em: 10 jan. 2013.

GIL, A. C. Como elaborar projetos de pesquisa. São Paulo: Atlas, 2010.

Grupo de Planejamento Organizacional. Relatório de atividades realizadas do Grupo de Planejamento Organizacional - GPL/PROMOEX. Disponível em: http:// www.controlepublico.org.br/index.php?option=com_docman\&Itemid=46. Acesso em: 5 dez. 2011.

Hoon, C. The "New Public Management" in the 1980s: variations on a theme. Accouting, Organization and Society, Oxford, v. 20, n. 2-3, p.93-109, 1995.

IsetT, K. R. Provan, K. G. The Evolution of Dyadic Interorganizational Relationships in a Network of Publicly Funded Nonprofit Agencies. Journal of Public Administration Research and Theory, v. 15, n. 1, p. 149-165, 2005.

Kickert, W. J, M.; Koppenjan, J. F. M. Public Management and Network Management: an overview. In: KICKERT, W. J. M. et alli (ed.). Managing Complex Networks Strategies for the Public Sector. London: Sage Publications, 1999. p. 35-61. 
KissLer, L.; Heidemann, F. G. Governança pública: novo modelo regulatório para as relações entre Estado, mercado e sociedade? Revista de Administração Pública, Rio de Janeiro, v. 40, no 3, p. 479-99, maio/jun. 2006.

KLInJ, E. H. Policy Network: an overview. In: KicKert W. J. M. et alli. (ed.). Managing Complex Networks Strategies for the Public Sector. London: Sage Publications, 1999. p. 16-35.

Kooiman, J.; Van Vliet, M. Governance and Public Management. In: Eliassen, K. A.; Koolman, J. Managing Public Organizations - lessons from contemporary European experience. Sage Publications, 1993. p. 58-72.

Lakatos, E. M. e Marconi, M. de A. Fundamentos de metodologia científica. 7. ed. São Paulo: Atlas, 2010.

Loureiro, M. R. Teixeira, M. A. C. Moraes, T. C. Democratização e reforma do Estado: o desenvolvimento institucional dos tribunais de contas no Brasil recente. Revista de Administração Pública, Rio de Janeiro, v. 43, no 4, p. 739-72, jul./ago. 2009.

Marini, C. Martins, H. Um governo matricial: estruturas em rede para geração de resultados de desenvolvimento. IX Congreso Internacional del CLAD sobre LA ReForma del Estado y de la Administración Pública, 2004, Madrid, España.

Martins, G. A.; Theóphilo, C. R. Metodologia da investigação científica para ciências sociais aplicadas. 2. ed. São Paulo: Atlas, 2009.

Mazzon, J. A.; Nogueira, R. Projeto de prestação de serviço especializado para realização de pesquisa e proposição de iniciativas para adequada implantação da Lei de Responsabilidade Fiscal (LRF) pelos tribunais de contas estaduais e municipais. São Paulo: FIA/USP, 2002. (Relatório de Pesquisa)

MintzBerg, H. Administrando governos, governando administrações. Revista do Serviço Público, Brasília, Ano 49, n. 4, p. 148-164, 1998. ENAP.

Pacheco, R. S. A agenda da nova gestão pública. In: Loureiro, M. R.; Abrucio, F. L. E; PAcho, R. S. (Org.). Burocracia e política no Brasil - Desafios para o Estado Democrático no Século XXI. Rio de Janeiro: FGV Editora, 2010. p. 183-218.

Portal dos Tribunais de Conta do Brasil. Promoex. Disponível em: http://www. controlepublico.org.br/index.php?option $=$ com_content\&view $=$ article\&id $=11 \&$ Ite mid=17. Acesso em: 31 out 2011.

Provan, K. G.; Milward, H. B. Do Networks really work? A Framework for evaluating Public-Sector Organizational Networks. Public administration review, 2001.

SECCHI, L. Modelos Organizacionais e Reformas da Administração Pública. Revista de Administração Pública: Rio de Janeiro, v. 43, n. 2, p. 347-69, mar./abr. 2009.

Silva, F. A. GonçAlves, C. A. O processo de formulação e implementação do planejamento estratégico em instituições públicas. Revista de Administração da UFSM, v. 4, p. 458476, 2011.

Triviños, A. N. S. Introdução à pesquisa em ciências sociais: a pesquisa qualitativa em educação. São Paulo: Atlas, 2007. 


\section{Resumo - Resumen - Abstract}

Redes organizacionais no contexto da governança pública: a experiência dos Tribunais de Contas do Brasil com o grupo de planejamento organizacional Flávia de Araújo e Silva; Túlio César Pereira Machado Martins e Ivan Beck. Ckagnazaroff

Este artigo buscou analisar as possibilidades de atuação integrada do grupo de planejamento organizacional, sob a perspectiva de organizações em rede. Trata-se de um grupo formado por integrantes das áreas de planejamento dos Tribunais de Contas do Brasil, com objetivo de discussão da temática do planejamento estratégico. A metodologia foi baseada em consulta a documentos e entrevistas aos membros do grupo, realizadas em dezembro de 2011. Foi descrita a forma como se deu a criação do grupo, os avanços alcançados e as dificuldades encontradas. Concluiu-se que a atuação conjunta apresentou muitos benefícios, pois os resultados alcançados vão desde aprimoramento dos procedimentos de gestão, até a economia gerada ao erário.

Palavras-chave: redes organizacionais; cooperação; Tribunais de Contas; setor público; Promoex

Redes organizacionales en el contexto de la gobernanza pública: la experiencia de los Tribunales de Cuentas de Brasil con el grupo de planificación organizacional Flávia de Araújo e Silva; Túlio César Pereira Machado Martins y Ivan Beck. Ckagnaz̧aroff

El presente artículo se configura como una investigación de las posibilidades de actuación integrada del grupo de planificación organizacional, desde la perspectiva de las organizaciones de la red. Desde un grupo formado por miembros de las áreas de planificación de losTribunales de Cuentas de Brasil, con el objetivo de discutir la temática de la planificación estratégica. La metodología se basó en los documentos de consulta, junto con entrevistas con los miembros del grupo. Se describe la manera cómo fue la creación del grupo, los progresos realizados y las dificultades encontradas. Al final, se concluyó que la acción conjunta tuvo muchos beneficios, por los logros que van desde la mejora de la gestión pública hasta la reducción del gasto generado al erario.

Palabras clave: redes organizacionales; cooperación; Tribunales de Cuentas; sector público; Promoex

Network organizations in the public sector: the case of the Brazilian Audit Courts and the Organizational Planning Group Flávia de Araújo e Silva; Túlio César Pereira Machado Martins and Ivan Beck. Ckagnazaroff

This paper aims to analyze the possibilities of integrated acting within the Organizational Planning Group under the perspective of network organizations. It is a group composed by members from the Planning Units of the Brazilian Audit Courts to discuss strategic planning issues. The methodological approach was based in documental research and interviews with members of this group. It was described the way the Group was created, the advances reached and the difficulties met. It was concluded that the interaction of the members brought many advantages because the results go from improvement in management procedures to economy generated to the exchequer.

Keywords: network organizations; cooperation; Audit Courts; public sector; Promoex 
Flávia de Araújo e Silva

É mestranda em Ciências Contábeis pela Universidade Federal de Minas Gerais e coordenadora no Tribunal de Contas do Estado de Minas Gerais. Contato: flaviaaraujos@yahoo.com.br

Túlio César Pereira Machado Martins

É especialista em Direito Tributário pela Pontifícia Universidade Católica de Minas Gerais e em Controle Externo e Avaliação da Gestão Pública pela Escola de Contas e Capacitação Professor Pedro Aleixo. Tem atuado como assessor do Tribunal de Contas do Estado de Minas Gerais. Contato: tuliommartins@gmail.com

Ivan Beck Ckagnazaroff

É doutor em Doctoral Programme Aston Business School pela Aston University e professor associado IV da Universidade Federal de Minas Gerais. Contato: ivanbeck00@gmail.com 